\title{
Alteridade do corpo do velho: estranhamento e dor na Saúde Coletiva
}

\author{
Alterity of the body of the elderly: estrangement and pain in Public \\ Health
}

Wagner Jorge dos Santos (https://orcid.org/0000-0001-5107-8519) ${ }^{1}$

Karla Cristina Giacomin (https://orcid.org/0000-0002-9510-6953) ${ }^{2}$

Josélia Oliveira Araújo Firmo (https://orcid.org/0000-0001-5330-476X) ${ }^{3}$

${ }^{1}$ Programa de Pós-

Graduação em Saúde

Coletiva, Instituto René Rachou/Fiocruz Minas. Av. Augusto de Lima 1715, Barro Preto. 30190-002 Belo Horizonte MG Brasil. wagnerkaritos@

yahoo.com.br

${ }^{2}$ Secretaria Municipal de Saúde de Belo Horizonte (SMSA-PBH). Belo Horizonte MG Brasil.

${ }^{3}$ Núcleo de Estudos em Saúde Pública e Envelhecimento (NESPE), Fundação Oswaldo Cruz MG. Belo Horizonte MG Brasil.

\begin{abstract}
In old age, the ailing patient's body becomes estranged and reveals an awareness of alterity. This paper investigates how the body of the elderly addresses the estrangement as a subject, producing its own actions in the experience of disease and practice of public health. The research, developed using the qualitative approach of an anthropological nature, is based on the assumptions of ethnography. Individual interviews with a semi-structured script in the universe of 57 elderly people were conducted. The methodology of Signs, Meanings and Actions oriented the data collection and analysis enabling the investigation of representations and concrete behaviors associated with the otherness of the body. There was the sense of production of otherness in relation to two analytical categories associated with aging and disease. A split between the active body of the memory and another experienced with limitations in the present is detected, reflecting the confrontation of self-care and adherence to treatment. The body of the elderly individual is heir to a body image that remodels constantly, depriving the elderly of their place as contemporary owners of their bodies, as they become other persons.
\end{abstract}

Key words Alterity, Body image, Pain, Illness, Elderly
Resumo Na velhice, o corpo doente torna-se estranho e revela uma consciência de alteridade. Este artigo busca investigar como o estranhamento corporal do velho o mobiliza como sujeito, produzindo os endereçamentos de ações próprias na experiência da doença e nas práticas da saúde coletiva. A pesquisa, desenvolvida na abordagem qualitativa de cunho antropológico, fundamentase nos pressupostos da etnografia. Foram realizadas entrevistas individuais com roteiro semiestruturado em universo de 57 idosos. A metodologia de Signos, Significados e Ações orientou a coleta $e$ análise dos dados possibilitando a investigação das representações e comportamentos concretos associados à alteridade do corpo. Observou-se o sentido da produção de alteridade em relação a duas categorias analíticas associadas ao envelhecimento e à doença. Nota-se uma cisão entre o corpo ativo da memória e outro vivido com limitações no presente, repercutindo no enfrentamento do autocuidado e adesão ao tratamento. O corpo do velho é herdeiro de uma imagem corporal que se remodela sem cessar, destituindo a pessoa idosa do seu lugar de sujeito contemporâneo de si mesmo, enquanto se torna outrem.

Palavras-chave Alteridade, Imagem Corporal, Dor, Doença, Idoso. 


\section{Introdução}

O tempo talha o corpo esculpindo de forma silenciosa e progressiva as marcas da existência humana. Envelhecer, para a maior parte dos ocidentais, é um movimento insensível, infinitamente lento, que configura a experiência do envelhecimento como um processo que escapa à consciência, pois nele nenhum contraste acontece ${ }^{1}$. Contudo, envelhecer com sofrimento rompe com o silêncio da consciência, pois o sofredor se conscientiza de um contraste entre seu corpo e ele mesmo ${ }^{2}$.

No percurso da existência o corpo original se torna múltiplo no advir de uma temporalidade implacável e interminável, subvertendo a identidade de querer ser único, configurando em si mesmo todos os marcadores biológicos e psicossociais que o modificam ao longo do tempo, enquanto se torna outrem. Nesse processo, o corpo enquanto órgão de mediação com o mundo ${ }^{3}$ se mostra múltiplo e polissêmico.

O corpo do velho é feito de muitas experiências, se entregando na vida ao demorado trabalho de luto que revela em si os sentidos da finitude $e^{4}$. Em um processo existencial de se desfazer de si mesmo, a pessoa idosa se percebe estrangeira, como nas palavras de Simone de Beauvoir: "eu me tornei outra, apesar de permanecer eu mesma", o que torna a velhice herdeira de uma imagem corporal que se remodela sem cessar ${ }^{1}$. Segundo Goldfarb 6 , o velho é sempre o outro em quem não nos reconhecemos, parecendo a imagem da velhice estar sempre fora, pertencente ao inquietante outro lado do estranho familiar.

Esse fato pode ser pensado a partir da definição e construção da imagem corporal, quando as doenças crônicas, a dor e o sofrimento participam como questões importantes da experiência humana $a^{7-9}$. As doenças crônicas promovem, ao longo de um moroso período de tempo, a desintegração da autoimagem das pessoas em pequenos fragmentos, sem que haja o desenvolvimento simultâneo de uma nova autoimagem igualmente valorizada ${ }^{7}$. Por sua vez, desde o nascimento, a dor, enquanto evento agudo, contribui para a construção da imagem corporal que começa a se formar, ajudando-nos a decidir quem e o que desejamos ter mais perto do ego e quem e o que desejamos manter o mais afastado possível dele? Porém, quando crônica, a dor impacta negativamente a autoimagem e a identidade de quem a experimenta, ao produzir uma imagem corporal depreciativa e debilitante para a pessoa que so$\mathrm{fre}^{8}$. Essa perda do senso de si mesmo representa a essência do sofrimento para essas pessoas ${ }^{7,8}$, que pode advir das doenças e ou da dor. Contudo, especialmente na velhice, o corpo que sofre não é mais dócil à vontade do sujeito, pois vivencia ainda outras perdas pessoais e funcionais para além da doença crônica e da dor. Nesse processo, o corpo do velho torna-se estranho e revela uma consciência de alteridade.

Essa experiência de produção de alteridade do (e no) corpo precisa ser articulada à maneira de ser no mundo e de ser para o outro no universo social da pessoa idosa. A experiência do processo saúde-doença configura-se como intercurso de alteridades entre o eu-são e o outro-doente, impondo diferenças e limites aos possíveis que a existência oferece ${ }^{10}$. Essa distância entre o normal e o patológico torna o velho doente diferente de si mesmo, posto que ao assumir a identidade de doente cria alteridade, constituindo-se numa marca da experiência da doença ${ }^{10}$, principalmente, na sua inserção no campo de atenção à saúde e das práticas de saúde coletiva.

Neles, a dor, o sofrimento e o mal-estar do corpo da pessoa idosa são codificados pela medicalização do tratamento, o que transforma o corpo doente do velho no último silencioso espaço dialógico de um homem incapaz de respostas, que enterra as perguntas no corpo, mistificando o discurso na distanciadora neutralidade dos mecanismos fisiopatológicos. Recusar ao corpo um valor comunicativo fecha o acesso a qualquer outra dimensão, a soluções do conflito em um horizonte humano ${ }^{11}$.

Discutir essas questões pode auxiliar a saúde coletiva a identificar e contrapor as demandas percebidas na cronicidade da dor e das doenças do corpo envelhecido, configurando na perspectiva das ciências sociais, uma compreensão das narrativas de sofrimento desse corpo em dor como experiência vivida ${ }^{12}$. O presente trabalho, reconhecendo a alteridade do corpo como elemento importante no cuidado à saúde, busca investigar como o estranhamento corporal do velho o mobiliza como sujeito, produzindo os endereçamentos de ações próprias na experiência da doença e nas práticas da saúde coletiva.

\section{Percurso metodológico}

O presente estudo, desenvolvido na perspectiva da abordagem qualitativa, de cunho antropológico, está fundamentado no espaço intersubjetivo de construção das relações na comunidade com as pessoas que compõem o nosso universo de pesquisa e por um tempo de diálogo que pudesse 
compreender o 'ponto de vista da pessoa idosa'. Essa pesquisa é parte do projeto "Abordagem Antropológica da Dinâmica da Funcionalidade em Idosos", conduzido na cidade de Bambuí, localizada a oeste de Minas Gerais. Este município, de 23 mil habitantes, passa por um progressivo fenômeno de urbanização e envelhecimento. Sua população urbana em 1950 representava 16\% da população total, tendo passado para $85 \% \mathrm{em}$ 2010; no mesmo período, os habitantes com 60 ou mais anos de idade passaram de menos de $4 \%$, para quase $16 \%$ em 2010, sendo $45 \%$ homens. Em 2010, a taxa de analfabetismo da população de 15 anos ou mais de idade era de 7,6\%, porém entre os idosos esse índice encontra-se em $22,1 \%{ }^{13,14}$.

Os critérios de inclusão dos idosos (idade $\geq$ 60 anos), cadastrados nas seis Unidades Básicas de Saúde do município, assistidos pela Estratégia Saúde da Família, buscaram garantir a heterogeneidade dos participantes quanto a: território das equipes, gênero, idade e condição funcional. Somente foram entrevistadas pessoas idosas sem alterações cognitivas, que impossibilitassem a realização das entrevistas e o critério de saturação regulou o tamanho do universo pesquisado.

O modelo de Signos, Significados e Ações ${ }^{15}$ orientou a coleta e análise dos dados. Este modelo apresenta-se como um instrumento privilegiado de investigação antropológica das representações e comportamentos concretos relativos à saúde/ doença predominantes na cultura local. Ele possibilita um conhecimento sistemático acerca dos elementos contextuais que intervêm na construção de comportamentos concretamente adotados (maneiras de agir) bem como o acesso a lógicas conceituais (maneiras de pensar) privilegiadas por uma dada população ${ }^{16}$ para compreender e explicar uma determinada condição ${ }^{17}$; na presente pesquisa, o estranhamento do corpo do velho.

Nessa perspectiva, a proposta metodológica escolhida ${ }^{18}$ inverte o procedimento geralmente utilizado nos estudos sobre representações e parte do nível pragmático para remontar ao nível semântico. O modelo Signos, Significados e Ações ${ }^{15}$ parte dos comportamentos concretos de indivíduos para identificar as lógicas conceituais que lhes são subjacentes e os diferentes fatores que intervêm na concretização destas lógicas em situações particulares ${ }^{19}$, permitindo a sistematização do pensar e agir singular no contexto da cultura local ${ }^{16}$. Para Geertz ${ }^{20}$ as ações cotidianas do sujeito humano permitem definir os códigos que estruturam o pensamento numa cultura lo- cal, conferindo um significado ao mundo e, permitindo assim, uma leitura direta da realidade.

As duas premissas do modelo de análise dos 'Signos, Significados e Ações” são baseadas na perspectiva de que cada comunidade privilegia uma explicação sobre seus problemas de saúde, motivando respectivamente certos tipos de ações e reações correspondente à maneira específica pensar/agir sobre o seu universo dos problemas de saúde na cultura local; e no fato de que existe continuidade entre a maneira pela qual uma comunidade percebe e interpreta seus problemas de saúde, desenvolvendo procedimentos mediados por suas características socioculturais que entendem possam resolvê-los. Essa especificidade da construção cultural de cada comunidade em conceber o seu próprio universo dos problemas de saúde sustenta certa continuidade entre a maneira de perceber e interpretá-los, e consequentemente, desenvolver procedimentos típicos de enfrentamento ${ }^{18}$.

Utilizou-se a entrevista individual, no domicílio, com roteiro semiestruturado, para ampliar o campo de fala dos idosos. As entrevistas foram gravadas e transcritas, permitindo a leitura atenta para identificação das categorias analíticas e a interação entre elas, bem como sua articulação com o contexto sociocultural vigente ${ }^{21}$.

A análise dos dados incluiu trabalho: (a) descritivo de organização, leitura panorâmica, identificação das categorias, leituras em profundidade, modificações nas categorias; e (b) teórico de relações com outros achados e interpretações presentes na literatura e em dados secundários.

As representações culturalmente constituídas das ações concretas de produção da alteridade do corpo possibilitam uma análise centrada no seu significado $^{22}$. Nessa perspectiva, a percepção de si mesmo face à imagem de um corpo envelhecido com incapacidade funcional articula-se com o seu contexto de produção material e simbólica, expresso nas narrativas individuais e intersubjetivas, e com as lógicas do campo social e cultural.

\section{Aspectos Éticos}

Este Projeto de Pesquisa foi aprovado no Comitê de Ética em pesquisa com seres humanos do Centro de Pesquisa René Rachou. Todos os participantes assinaram um termo de consentimento livre e esclarecido, em acordo com a Resolução no 466, de 12 de dezembro de 2012 do Conselho Nacional de Saúde. 


\section{Resultados e discussão}

O universo pesquisado foi composto por 27 homens e 30 mulheres, com idades entre 62 e 96 anos, todos residentes em Bambuí-MG. Quanto ao estado civil, vinte e quatro eram casados, um em união estável, sete solteiros, e vinte e cinco viúvos; sendo que a maioria teve filhos. Prevalecem a baixa escolaridade e a origem rural, com forte predomínio da religião católica. Os principais motivos de mudança para a cidade foram a maior proximidade com o serviço de saúde e/ ou com a escola para os filhos. Todos os participantes responderam a questões referentes às suas percepções de saúde.

Após várias leituras das entrevistas, sob um olhar específico e cuidadoso, a alteridade foi identificada no campo de fala dos idosos como significado, a partir da qual foram discriminadas duas categorias analíticas de acordo com os signos percebidos e associados pelos sujeitos pesquisados às ações da vivência da dor e experiência corporal da incapacidade funcional: "Alteridade e estranhamento do corpo envelhecido" e a "Alteridade e dor no adoecimento do corpo do velho". Esse recorte foi julgado relevante, pois representa o sentido das ideias dos sujeitos pesquisados.

\section{Alteridade e estranhamento do corpo envelhecido}

Os entrevistados relatam sua condição corporal referindo-se a partes adoecidas ou limitadas do corpo como se se tratasse de um objeto externo e próximo de si: Mas hoje, esse braço aqui já não aguenta. Sinto uma dor no braço aqui. Já não aguento jogar massa, mexer com massa. Mais, é ficar à toa. (H46, 90 anos, viúvo); Mas é essa escadeira que não me dá sossego (M53, 82 anos, viúva); Eu fico assentado, não tem jeito de fazer mais nada. A perna não ajuda. (H50, 96 anos, casado). Perguntada se consegue andar carregando alguma coisa uma senhora afirma: Consigo. Pouco, o que não pesa muito por causa do braço. Esse braço tem que levar ele lá em cima e trazer de novo (M55, 86 anos, casada).

$\mathrm{Na}$ percepção dos sujeitos pesquisados esse afastamento dos membros limitados e ou adoecidos produz um estranhamento em relação ao corpo envelhecido, nomeado na terceira pessoa, como se dele somente pudessem dizer à distância. Assim, o velho estabelece uma relação de distanciamento com seu corpo sofredor quando o nomeia em terceira pessoa, falando do próprio corpo como se fosse outro. Para Goldfarb ${ }^{6}$, esse estranhamento da pessoa que envelhece e diz diante de sua imagem corporal “esse não sou eu”, revela uma falta de reconhecimento como imagem, não como sujeito.

Entretanto, o corpo envelhecido se transforma em elemento de incômodo e dor do qual o idoso busca se afastar, enquanto a parte doente passa a ser presença estranha que lhe faz oposição e com a qual não mais se identifica como sujeito, assumindo uma perspectiva corporal persecutória em relação à própria vida, bem como algo que necessita ser tutelado, por si ou por terceiros. Em estudo semelhante, Osborn e Smith ${ }^{2}$, através de uma análise fenomenológica interpretativa entre europeus caucasianos que vivenciavam dor crônica associada com altos níveis de angústia e incapacidade, mostrou que o corpo indolor ocupa um papel pequeno na percepção de si mesmo, mas quando alguma parte do corpo dói, ela é referida como excluída de si mesmo, produzindo sentidos de ser estrangeira e suprimida como "não eu", deixando de participar do seu autoconceito preferido. Esses achados mostram a relação complexa entre o corpo, a dor crônica e a percepção de si, evidenciando que o dissabor encarnado da dor crônica envolve um assalto e uma defesa da percepção de si preferida ou desejável da pessoa.

Outra senhora muito idosa reconhece: Tem dia que eu fico olhando minhas mãos assim e pensando: gente, quantos murros deu essas mãos! Agora eu não posso fazer nada? (M8, 83 anos, viúva). Nota-se nítida cisão entre a pessoa que fala e a parte do corpo que não se lhe submete, configurando a separação entre o corpo ativo distante no passado, registrado na memória, e esse outro vivido no presente. Diferentemente daquele que desempenhava com desenvoltura as tarefas que lhe eram demandadas, o corpo atual se mostra desobediente, traumático e gerador de sofrimento e, talvez por isso, os idosos experimentem tamanho estranhamento face a esse "outro" corpo que age diferente do passado. Nesse contexto, o corpo altera a experiência das atividades da vida diária e se manifesta perfeitamente estranho na mutabilidade de seu comportamento exterior ${ }^{23}$.

Morley $^{24}$ aborda a questão do impacto da dor na percepção da experiência corporal de muitas pessoas que se referem a uma sensação de alienação do corpo. Para esses, a experiência da dor lhes confere o sentido de que seu corpo não é o que eles esperavam, mas tendo antecipado para esta etapa de seu desenvolvimento. Isso às vezes é capturado com uma frase como velho antes do meu tempo, refletindo as mudanças na funcionalidade do corpo. 
Cada sujeito constrói sua própria imagem, profundamente ligada à sua história e vivência relacional ${ }^{6}$, tendo o corpo vivido como mediador entre o sujeito e o mundo. Nessa perspectiva, a alteridade passa a ser pensada como elemento constitutivo da individualidade ${ }^{25}$, deixando de denotar somente a relação com outrem, mas estendendo-se à relação com o si mesmo de uma existência corporal, que a seu turno se transforma nas relações com outrem e com a própria subjetividade no curso da vida. Essa alteridade, a um só tempo estranha e íntima, compõe a ideia de um si mesmo, traduzindo o sentido que "rodeia o mesmo enquanto outro que ele mesmo" 3 .

Uma idosa descreve o sentido de mudança percebido com o passar dos anos: Ih, vai mudando demais! Nossa Senhora! Às vezes tem dia que a gente quer fazer as coisas, sabe fazer, dá conta, dava conta e agora já não dá. A idade vai acabando com a gente (M27, 80 anos, solteira). Ao falar de si, um senhor rememora: Ah gente, eu já trabalhei muito na minha vida, trabalhei na roça, fui criado na roça, trabalhando. Plantava roça, essas coisas assim. Agora a gente não dá conta mais de mexer com nada. Tem que ficar comendo o que tá feito. (H45, 92 anos, viúvo). Reboussin et al. ${ }^{26}$ concluíram que para as pessoas idosas existe uma clara distinção entre a função corporal e a aparência do corpo, sugerindo que os idosos podem valorizar a funcionalidade corporal mais que a aparência do corpo.

Nesse sentido, na sua maneira de pensar e agir, o signo não dou conta presente no campo de fala dos idosos identifica uma habilidade que se exauriu e agora não dá mais conta, revelando a condição de incapacidade funcional na cultura local ${ }^{27}$. Esse corpo velho produzido ao longo da vida requer uma alteridade radical que ocupe a funcionalidade faltante daquilo que não consegue mais fazer sem ajuda. Por sua vez, o signo comer o que tá feito lhes anuncia sua impotência diante da dependência de outrem, ao seu próprio desamparo face ao inexorável da vida, e remete à inescapável finitude geradora de angústia e medo $^{3}$. No cotidiano da vida, os signos não possuem existência autônoma, mas se configuram pragmaticamente com valor de signo a partir da contextualização no sistema de referência sociocultural utilizado pelo intérprete ${ }^{28}$.

Envelhecer se constrói na perspectiva de uma transformação permanente de tornar-se outro, a partir de uma infinidade de corpos alteridades que o indivíduo experimenta ao longo do tempo. Essa mutação involuntária confronta o humano com a sua própria diferença: como parte de uma metamorfose, o envelhecimento produz no corpo o sentido próprio de uma alteridade que se instala a cada tempo na singularidade de cada um. Essa alteridade já não é mais o sentido daquele que é outro homem, mas o outro no homem ${ }^{29}$.

É próprio da condição humana experimentar o corpo do presente, mesmo que os registros da experiência remetam a um corpo que é alter na sua intimidade. Ao olhar o corpo limitado na sua função e atividade, o sujeito idoso apresenta dificuldades em vislumbrar o que ainda é possível realizar. Observa o passado desse corpo que produzia e considera o presente como um tempo de falta que o distancia do ideal de si mesmo. Por sua vez, a imagem de um corpo envelhecido que não corresponde mais à imagem da memória é a imagem apavorante de um espelho que antecipa ou revela a velhice ${ }^{6}$ e a morte . $^{4}$

Um senhor ao ser indagado sobre a contribuição do tempo em relação à vida relata: Só tragédia né [risos]. A idade só traz ruindade. As coisas que tem vontade de fazer não faz mais, ir para o forró, eu já gostei de forró. Então é coisa de quê? É, é coisa da idade. (H23, 82 anos, casado). Uma senhora explica: Ah, parece que sempre teve um tempo que a gente lavava roupa, fazia muita coisa. Eu lavava roupa, lavava as coisas, gostava de lavar. Depois eu fui ficando velha, eu fui ficando velha $e$ ... (M31, 77 anos, viúva).

$\mathrm{Na}$ medida em que o vivido insiste em lhe lembrar de um corpo passado idealizado, o corpo real, envelhecido e funcionalmente limitado produz a experiência dolorosa de não ser mais o que era. Na cultura local do universo pesquisado, o corpo outrora capaz de produzir não existe mais e lhes desvela a ausência da própria vida, reproduzindo a ideia do homem como objeto da produção ${ }^{30}$, e, portanto, na exigência do olhar coletivo no qual o idoso se mira, tampouco encontra o suporte necessário para se reconhecer como sujeito de sua própria referência.

O tempo da vida associado à mudança, à descontinuidade, à diferença, à ruptura, também se configura como alteridade na medida em que traz para existência a dualidade dos sentidos positivos e negativos que compõem o cotidiano do envelhecimento humano. Ao invés dos registros cronológicos das experiências do existir, o corpo envelhece ao ritmo da vida e não do tempo ${ }^{31} \mathrm{e}$ o envelhecimento é percebido no corpo, a partir das impressões que a vida deixa. No advir do envelhecimento, a alteridade configura-se na individualidade. Corpo e tempo se entrecruzam e a seu modo vão produzindo várias velhices ${ }^{6}$ e outras tantas imagens. 


\section{Alteridade e Dor no Adoecimento do Corpo do Velho}

Em relação às suas expectativas, dois idosos narram os seus medos: Isso aí o que eu mais tô com medo. É disso, igual muita gente. Estas doenças acabam cortando a perna, o braço. Isso daí a gente tem medo. Ah que não é fácil. Cê vê, a gente nasce perfeito e morre aleijado (M24, 86 anos, viúva); A mão, não posso confiar nela em nada. Se eu pegar um prato, um troço que não possa (cair), cai [...] Agora, o pé também é preciso eu tá de olho nele. Atrapalha... (H9, 74 anos, casado).

Esse corpo depositário de memórias se transforma com o adoecimento e experimenta a metamorfose resultante da experiência e dos efeitos da doença ao longo do tempo. Esse outro possível no corpo do velho não é mais percebido como um aliado, pois estabelece para o sujeito idoso uma relação de distanciamento com seu corpo e desconfiança ante as partes que não mais respondem ao sentido da funcionalidade esperada. Por conseguinte, observa-se um paradoxo: submisso à doença e à dor o corpo fica reduzido às suas partes afetadas, mas é na desobediência do membro adoecido que o corpo manifesta o sentido de autonomia próprio de uma alteridade. A alteridade que se instala no cerne da corporeidade, e pela qual faz o corpo doente parecer outro, implica o retorno da atenção para esse corpo e, a partir dele, para toda a existência ${ }^{10}$.

Um senhor constata que a perna ficou bamba e está frouxa: Não firma (as pernas). Parece que... não é como era. [...] Uai, o que mudou é que, eu gostava de sair e caçar, sabe, ir pro mato caçando, quando eu aposentei, agora eu não posso sair, fico querendo o rio e não posso. É ficar quieto. (H46, 90 anos, viúvo).

Maldonato ${ }^{11}$ entende esse sentimento como a nostalgia que se inscreve no horizonte do tempo, configurando os sentidos de um tempo concluído, que já foi e é impossível retornar. O tempo, embora ainda se tenha um espaço de percurso, se vê confrontado com outro tempo que não mais nos pertence e não pode mais voltar. Etimologicamente, nostalgia tem raízes no prefixo nosto (retorno) e no sufixo algia (dor) e conceitua a produção de lembranças de um espaço temporalmente vivido do qual se desgarrou ou foi afastado, produzindo sentimento de distância e exílio. Assim o corpo do velho é lembrança, temporalidade encarnada, alteridade presente que produz todos os significados de um corpo nostalgia.

Indagado sobre como saber que uma pessoa está com a saúde ruim, um idoso responde: $E u$ acho que a pessoa é igual um carro, faz barulho, aparece sabe alguma coisa, você sente uma dor de cabeça, você sente uma tonteira, você sente uma dor nas costas, você sente uma dor no peito. Então o quê que acontece, você apareceu uma coisa, você tem que procurar um médico e ver o quê que ta acontecendo (H18, 65 anos, casado). Apesar disso, ele admite agir de modo diferente: Eu não fico procurando. É igual você pegar um carro, um carro velho. Se você for com ele pro mecânico todo dia, você acha defeito pra ele todo dia. Você vai convivendo. Porque se você começar levar ele pro mecânico num primeiro barulhinho, aquilo lá às vezes tá tudo bom, você pensa assim: tem um barulhinho aí. Tira esse barulhinho e aparece um outro barulhinho. (H18, 65 anos, casado).

O corpo doente da velhice é percebido e tratado de modo fragmentado, o que pode justificar a procura ou não por cuidado em saúde. Essa fragmentação do corpo indica que o idoso se faz conhecer nas partes, sem ser conhecido no todo do sujeito. Entretanto, a doença não é apenas um local do corpo, mas concerne toda a existência como aspecto da corporeidade ${ }^{10}$.

Uma idosa responde sobre a sua percepção de como é uma pessoa doente: Uai, eu vejo assim, porque a pessoa que tá doente, ele entristece, ele não anda, ele não come direito. Não sei, ele fica uma pessoa neutra.... Solicitada a explicar o sentido do que quer dizer uma pessoa neutra, explica: Ele fica assim, parece que ele quer ficar só calado, só sozinho, só... não pensa. E quando indagada se o estado neutro da pessoa doente é porque ela escolhe ou não essa condição, ela responde: Ahé $a$ doença! A doença! Não consegue dominar a doença. A doença que provoca o jeito dela ficar. (M5, 77 anos, viúva).

O sujeito do corpo na velhice é neutralizado pela doença que o desempodera de si mesmo, produzindo um corpo apagado da presença do sujeito que, por sua vez, se torna neutro. O sujeito sem presença é neutro e desinvestido da vida, sem vínculo consigo mesmo e com os outros. Essa perspectiva corrobora o fato de que a dor é monossêmica e diante dela a pessoa se retrai do mundo, sendo que somente as relações do homem com os dados de seu universo sociocultural é que lhe confere significados ${ }^{10}$ na troca entre pares.

Uma idosa relata sua vivência de dor: Parece que os ossos cortam. Tudo dói: as mãos, os dedos, dói de mais! Tem dia que dói! Passo sem dormir [...] Essa noite eu não dormi. Dor no corpo, dor... os ossos, então fica doendo demais, isso tudo dói que Nossa Senhora! Ferroa tudo assim! Às vezes eu to 
assim sentada dá aquelas agulhadas no meu corpo. Aí eu fico quieta. (M8, 83 anos, viúva). A alteridade do corpo produz o estranho familiar de quem sente a dor de não se querer conhecer no corpo velho e doente, restando-lhe a resignação de se aquietar. A dor do corpo que envelhece e adoece produz na existência esse momento em que se confirma para a pessoa a impressão de que seu corpo não é ele ${ }^{32}$.

Quando a vivência da dor impõe limitações ao modo de ser usual do indivíduo, percebe-se a alteridade no corpo doloroso mediada por um estranhamento face à imagem corporal. A doença cria uma alteridade no próprio sujeito, uma vez que na dor o corpo não se submete à vontade da pessoa que sofre, manifesta característica própria de corpo doente, torna-se um estranho e revela uma consciência de alteridade ${ }^{10}$. Nessa perspectiva, o estrangeiro não é mais o outro, mas sua condição de estrangeiro passa a pertencer à subjetividade encarnada no corpo, fazendo com que o sujeito deixe de ser contemporâneo de si mesmo $^{33}$.

Ao ser indagado se é ruim a fase da dor, um idoso responde: É muito ruim pelo seguinte: pelas dores que são demais. Essa condinite causa muita dor, a gota causa muita dor, agora ainda veio essa artrose no joelho. (H43, 62 anos, casado). $\mathrm{Na}$ cultura local, o corpo adoecido é invadido pela doença que vem e entra se instalando no íntimo do corpo impondo uma realidade dolorosa. Da mesma forma, a doença é o objeto estranho que precisa sair do corpo, configurando no encaminhamento para a desincorporação desse objeto invasor e alheio à pessoa, o objetivo das práticas em saúde: Mas os médico é bom boba, porque a doença mesmo é que não sai (M24, 86 anos, viúva). O significado definidor da experiência de doença é próprio de uma incorporação/desincorporação em que o objeto estranho invade e sai da intimidade do corpo. Nesse sentido, os significados partilhados na cultura local influenciam a maneira como os indivíduos percebem a doença, vivenciam sua dor, interpretam seu sofrimento e estabelecem relações com os diversos sistemas de saúde ${ }^{34}$.

Canguilhem $^{35}$ aborda essa concepção de doença representada na dinâmica localizante de luta do organismo contra um ser estranho, combinando as afecções parasitárias com a ideia da doença-possessão. Para essa concepção, expulsar vermes e micróbios é recuperar a saúde, pois entende que a doença entra e sai do homem como por uma porta. Na especificidade da cultura local, o modo de pensar e agir do universo de pesquisa sobre o processo saúde doença é fortemente marcado pelo fato de Bambuí ter sido área endêmica para doença de chagas ${ }^{36}$, cuja transmissão da infecção pelo Trypanosoma cruzi constrói uma representação localizante de doença. Essa questão pode jogar luz sobre o fato do universo de pesquisa ter a concepção de que a velhice é doentia ${ }^{37}$, configurando nessa perspectiva a representação da velhice-doença que vem de fora e me invade, sendo localizada nas partes e membros contaminados do corpo.

Portanto, é fundamental compreender, a partir da perspectiva de alteridade, a experiência do sujeito idoso diante da vivência de sua imagem corporal, de sua dor e de possíveis doenças, cujas repercussões interferem no seu cotidiano e por vezes impõem a necessidade de cuidados crônicos ou mesmo a dependência de terceiros. Dessa maneira, quais as articulações possíveis que a alteridade do corpo do velho traz para maneira de ser da pessoa idosa em seu universo sociocultural e, principalmente, na sua inserção no campo de atenção à saúde e cuidado na saúde coletiva?

Ao sofrer mudanças ao longo do tempo, muitas questões emergem: O idoso percebe seu corpo como estranho somente como imagem ou igualmente como sujeito? Qual efeito da imagem corporal sobre a implicação do sujeito no cuidado de si e aderência ao tratamento? Se a pessoa idosa não se reconhece no seu corpo velho, doente e incapaz então qual corpo tratar/cuidar? Se para o sujeito e sua imagem o corpo simultaneamente percebe e é percebido ${ }^{38}$, a questão posta é: quem cuida e de quêe?

\section{O cuidado entre a Nostalgia da Imagem e a Esperança do Sujeito}

Uma idosa responde sobre as dificuldades nas atividades cotidianas: Eu faço assim, quando a gente não dá conta de nada mais eu tenho que largar. Vai largando! (M4, 81 anos, viúva). O signo "largar" revela a estratégia de desistência do sujeito que se entrega a uma nova realidade corporal que se impõe, caracterizando um deliberado impedimento do seu corpo de se relacionar com a vida plenamente ${ }^{39}$.

Um idoso fala de alguém com uma saúde ruim: A vida dele... Ele tinha mais idade do que eu, ele não importava de ficar doente não. Às vezes até: ah se morrer, não tem problema! (H6, 62 anos, casado). No campo da saúde, essa modalidade de enfrentamento da doença na velhice se configura como autoabandono no qual a pessoa não se faz presença no seu corpo, dificultando sua con- 
vocação como sujeito que cuida de si. Para lidar com esse corpo alteridade, os idosos pesquisados ao abrirem mão de ser como antes, desistem de construir para si um corpo possível para o tempo de hoje, e, portanto, de certo modo, desistem de atuar na vida, metaforizando o luto pelo próprio corpo de hoje que se apresenta incapaz.

Nesse sentido, a pessoa idosa perde a referência de si mesmo para afirmar sua concordância em se submeter a um determinado tratamento ou regime de intervenção. Se o corpo doente na velhice é um corpo "outro" diferente daquele ao qual o sujeito imaginariamente se identifica, prejudicado ficará os processos de aderência às práticas de cuidados. Estamos sempre nos separando de um corpo de outrora, mas não podemos nos separar de nós mesmos.

Assim, a alteridade do corpo na velhice quando não se reconhece historicamente inscrita como experiência passado-presente que unifica e referência a experiência do viver, o futuro se apaga como possibilidade. Prender-se na nostalgia de um corpo outro do passado causa muito sofrimento, sendo incontestavelmente um sentimento muito doloroso ${ }^{40}$. Essa é, portanto, uma vivência que se esvazia por não produzir o encontro da pessoa com a sua história e sentido de potencialidade e esperança.

Uma idosa relata suas consultas no posto de saúde: ... consulto diariamente porque não sara, mas a gente fica naquela fé que vai sarar, mas o médico ótimo me desanimou que isso é idade, que eu tenho que aceitar. (M24, 86 anos, viúva). O saber biomédico expresso na cultura local não ilumina o abismo que separa a idolatria da visão mecanicista e desumana que privilegia a gestão da doença em detrimento do cuidado do doente; que concebe as intervenções como procedimentais em detrimento da compreensão do trabalho em saúde como produção de vínculos ${ }^{37}$.

Fundamentalmente as relações de cuidado ${ }^{37}$ mediadoras do encontro usuário/profissional, configuradas no campo relacional em saúde, poderiam promover a aproximação do sujeito com o seu corpo, de tal maneira que ele pudesse readquirir uma unidade de sujeito com a imagem do corpo que lhe causa estranhamento e dor. Assim, a alteridade assume um papel preponderante na questão da ética do cuidado, pois ao ser removido das relações de cuidado, o diálogo não se estabelece e o cuidado pode não se efetivar ${ }^{41}$.

Entre a nostalgia e a esperança de uma nova história para o corpo do velho, o médico conde- na a não ter esperança e ao aprisionamento desse corpo alteridade no lugar que compreende a velhice como doença e os agravos como coisas da idade $^{37}$. A escuta de uma palavra livre desse olhar desestimulante poderia ajudar o velho a ser sujeito de sua história corporal, ocupando de si no autocuidado e na adesão ao tratamento.

Assim para viver a alteridade do corpo velho é preciso esperança, pois a nostalgia fala de um tempo irrevogável ${ }^{11}$. É como diz Álvaro de Campos (Fernando Pessoa): "Lisboa torno a te ver, mas a mim não me revejo"42.

\section{Considerações finais}

A alteridade do corpo doente na velhice constitui-se em dimensão importante da corporeidade do sujeito idoso, que perpassa os significados presentes na experiência corporal e subjetiva da incapacidade funcional. O corpo que envelhece com doença é sentido como estranho podendo ser percebido como se tratasse de outro corpo que o habita, configurando a experiência corporal em um entretempo constituído na memória de um corpo ativo e outro de realidade funcional incapaz que não lhe garante vivência plena com a vida.

Nessa temporalidade múltipla, a alteridade enquanto qualidade daquilo que é outro denuncia na incapacidade funcional o sentido de que o corpo doente na velhice não é mais o mesmo, estando esfacelado na pluralidade de suas identidades. O desafio para a pessoa idosa é superar na alteridade do corpo a vivência da ruptura biográfica, transformando o tempo da descrição densa da vida na conexão do presente com o passado e o futuro. Nessa condição, a vida ganha unidade e o corpo readquire o seu direito à singular pluralidade de múltiplas identidades.

$\mathrm{Na}$ velhice, o imprescindível diálogo com a consciência do si mesmo possibilita a transformação e a qualificação das relações com outrem e com a própria subjetividade que compõem o vivido e se inscrevem no imaginário e no próprio corpo, múltiplo e polissêmico na mediação com o mundo. Da mesma maneira, no campo da saúde é preciso ressignificar o olhar da pessoa idosa para o seu próprio corpo, nas práticas de autocuidado, mas na experiência da dor e do estranhamento/alteridade do corpo envelhecido auxiliá-la a se reencontrar consigo e acreditar na potência do cuidado da saúde coletiva. 


\section{Colaboradores}

WJ Santos trabalhou na concepção do projeto, análise e interpretação dos dados e redação do artigo. KC Giacomin trabalhou na concepção do projeto, análise e interpretação dos dados, e revisão crítica relevante do conteúdo intelectual. JOA Firmo trabalhou na concepção do projeto, coleta, análise e interpretação dos dados, e na revisão e aprovação final da versão a ser publicada.

\section{Referências}

1. Le Breton D. Antropologia do Corpo e Modernidade. Petrópolis, RJ: Editora Vozes; 2011.

2. Osborn M, Smith JA. Living with a body separate from the self. The experience of the body in chronic benign low back pain: an interpretative phenomenological analysis. Scand J Caring Sci 2006;20(2):216-222.

3. Botton JB. Promessa e atestação de si em Paul Ricouer. Intuitio 2009;2(2):145-151.

4. Giacomin KC, Santos WJ, Firmo JOA. O luto antecipado diante da consciência da finitude: a vida entre os medos de não dar conta, de dar trabalho e de morrer. Ciên Saude Colet 2013;18(9):2487-2496.

5. Beauvoir S. La vieillesse. Paris: Gaallimard; 1970.

6. Goldfarb DC. Corpo, tempo e envelhecimento. São Paulo: Casa do Psicólogo; 1998.

7. Charmaz K. Loss of self: a fundamental form of suffering in the chronically ill. Sociol Health Illn 1983;5(2):168-195.

8. Smith JA, Osborn M. Pain as an assault on the self: an interpretative phenomenological analysis. Psychol Health 2007;22(5):517-534.

9. Scatolin HG. A imagem do corpo: as energias construtivas da psique. Psic Rev 2012;21(1):115-120.

10. Venâncio S, Olivier GGF. A Doença e o Doente: uma abordagem através dos mitos. Impulso, Revista de Ciências Sociais e Humanas 1999;10(23/24):99-110.

11. Maldonato M. Passagens de tempo. São Paulo: Edições Sesc SP; 2012.

12. Bendelow GA. Pain, suffering and risk. Health Risk Soc 2006;8(1):59-70.

13. Instituto Brasileiro de Geografia e Estatística (IBGE). Dados gerais e informações estatísticas da cidade de Bambuí [página na Internet]. 2010 [acessado 2016 Abr 5]. Disponível em: https://cidades.ibge.gov.br/ brasil/mg/bambui/panorama

14. Instituto Brasileiro de Geografia e Estatística (IBGE). Séries Históricas e Estatísticas [página na Internet]. 2010 [acessado 2016 Abr 5]. Disponível em: https:// seriesestatisticas.ibge.gov.br/lista_tema.aspx?op $=0 \&$ no $=10$

15. Corin E, Uchôa E, Bibeau G, Kouma-Re B. Articulation et variations des systèmes de signes, de sens et d'actions. Psychopathol Afr 1992;24:183-204.

16. Uchôa E, Vidal JM. Antropologia Médica: Elementos Conceituais e Metodológicos para uma Abordagem da Saúde e da Doença. Cad Saude Publica 1994;10(4):497-504.

17. Firmo JOA, Lima-Costa MFF, Uchôa E. Projeto Bambuí: maneiras de pensar e agir de idosos hipertensos. Cad Saude Publica 2004;20(4):1029-1040.

18. Corin E, Bibeau G, Martin JC, Laplante R. Comprendre pour Soigner Autrement. Repères pour Régionaliser les Services de Santé Mentale. Montréal: Presses de l'Université de Montréal; 1990.

19. Corin E, Uchôa E, Bibeau G, Harnois G. Les Attitudes Dans le Champ de la Santé Mentale. Repères Théoriques et Méthodologiques pour une Étude Ethnographique et Comparative. Rapport Technique. Montréal: Centre de Recherche de l'Hôpital Douglas, Centre Collaborateur OMS; 1989.

20. Geertz C. Local Knowledge. Further Essays in Intrepretive Anthropology. New York: Basic Books, 1983. 
21. Giacomin KC, Uchoa E, Lima-Costa MFF. Projeto Bambuí: a experiência do cuidado domiciliário por esposas de idosos dependentes. Cad Saude Publica 2005;21(5):1509-1518.

22. Gomes R, Mendonça EA, Pontes ML. As Representações Sociais e a Experiência da Doença. Cad Saude Publica 2002;18(5):1207-1214.

23. Maldonato M. Consciência da temporalidade e temporalidade da consciência. Rev Latinoam Psicopat Fund 2008;11(1):39-54.

24. Morley S. Psychology of pain. Br J Anaesth 2008; 101(1):25-31.

25. Augé M. Não-lugares: introdução a uma antropologia da supermodernidade. Campinas, SP: Papirus; 1994.

26. Reboussin BA, Rejeski WJ, Martin KA, Callahan K, Dunn AL, King AC, Sallis JF. Correlates of satisfaction with body function and body appearance in middleand older aged adults: The activity counselling trial (ACT). Psychology and Health 2000;15(2):239-254.

27. Pereira JK, Firmo JOA, Giacomin KC. Maneiras de pensar e de agir de idosos frente às questões relativas à funcionalidade/incapacidade. Ciên Saude Colet 2014;19(8):3375-3384.

28. Corin E. Présentation. Les détours de la raison. Repères sémiologiques pour une anthropologie de la folie. Anthropologie et Sociétés 1993;17(1-2):5-20.

29. Vernant JP. A morte nos olhos. Rio de janeiro: Jorge Zahar; 1973

30. Schimidt TCG, Silva MJP. Percepção e compreensão de profissionais e graduandos de saúde sobre o idoso e o envelhecimento humano. Rev Esc Enferm USP 2012;46(3):612-617.

31. Augé M. Une ethnologie de soi: le temps sans âge. Paris: Seuil; 2014.

32. Le Breton D. Antropologia da Dor. São Paulo: Editora Fap-Unifesp; 2013.

33. Menezes MM. A Linguagem do Dizer em um Corpo que se apresenta como Ético. VERITAS 2007;52(2):6777.

34. Oliveira FA. Antropologia nos serviços de saúde: integralidade, cultura e comunicação. Interface (Botucatu) 2002;6(10):63-74.
35. Canguilhem G. O normal e o patológico. $5^{\mathrm{a}}$ ed. Rio de Janeiro: Forense Universitária; 2002.

36. Lima-Costa MF, Firmo JOA, Uchôa E. A estrutura da auto-avaliação da saúde entre idosos: projeto Bambuí. Rev Saude Publica 2004;38(6):827-834.

37. Santos WJ, Giacomin KC, Firmo JOA. Avaliação da tecnologia das relações de cuidado nos serviços em saúde: percepção dos idosos inseridos na Estratégia Saúde da Família em Bambuí, Brasil. Ciên Saude Colet 2014;19(8):3441-3450.

38. Peixoto AJ. Os sentidos formativos das concepções de corpo e existência na fenomenologia de Merleau-Ponty. Rev Abordagem Gestalt 2012;18(1):43-51.

39. Santos WJ, Pereira JK, Giacomin KC, Firmo JOA. Enfrentamento da incapacidade funcional por idosos por meio de crenças religiosas. Ciên Saude Colet 2013;18(8):2319-2328.

40. Minkowski E. Breves reflexões a respeito do sofrimento, aspecto pático da existência. Ver Latinoam Psicopatol Fundam 2000;3(4):156-164.

41. Hames MLC, Carraro TE, Ramos FR, Tholl AD. A alteridade como critério para cuidar e educar nutrizes: reflexões filosóficas da prática. Rev Bras Enferm 2008;61(2):249-253.

42. Pessoa F. Poesias de Álvaro de Campos. Lisboa: Ática; 1944 (imp. 1993).

Artigo apresentado em 08/07/2016

Aprovado em 06/04/2018

Versão final apresentada em 08/04/2018 